\title{
MONOTONE DYNAMICS OR NOT? DYNAMICAL CONSEQUENCES OF VARIOUS MECHANISMS FOR DELAYED LOGISTIC GROWTH
}

\author{
TORSTEN LINDSTRÖM
}

Abstract. In this paper we interpret the global stability properties of the delayed single species chemostat in terms of monotone dynamics on an asymptotically invariant hyperplane in the state space. The consequence is a translation of advanced analysis and delay differential equations into sign checks and ordinary differential equations for an important single species model with explicit resource dynamics. Complete proofs are included, since the limiting behavior at asymptotically invariant sets may not agree with the limiting behavior of the original system even in the finite dimensional case (Thieme (1992)).

A delayed logistic equation based on explicit resource dynamics falls out as a limiting case of the chemostat and we claim this to be a new mechanistic interpretation of delayed logistic models. We continue by comparing these results to several other delayed logistic models that has been mechanistically justified in the literature. We conclude that monotone dynamics apply in several cases. We improve one global stability result that cannot be obtained with by the use of monotone dynamics and end up by pointing out the dynamical differences between Hutchinson's (1948) delayed logistic equation and those with mechanistic interpretations.

Mathematics subject classification (2010): 34K20, 92D40.

Keywords and phrases: Delayed chemostat, global stability, Wright's equation, comparison techniques, Huchinson's logistic model, Blowfly equation, asymptotic invariance.

\section{REFERENCES}

[1] J. ARINO, L. WANG, AND G. S. K. WolkowiCZ, An alternative formulation for a delayed logistic equation, Journal of Theoretical Biology 241 (2006), 109-119.

[2] B. BÁnhelyi, T. Czendes, T. KRISTin, AND A. Neymaier, Global attractivity of the zero solution for Wright's equation, SIAM Journal of Applied Dynamical Systems 13 (2014), 537-563.

[3] C. Conley, Isolated Invariant Sets and the Morse Index, Regional conference series in mathematics, 0160-7642; 38. Providence, R. I: American Mathematical Society, 1978.

[4] K. L. CoOKE, Stability analysis for a vector disease model, Rocky Mountain Journal of Mathematics 9, 1 (1979), 31-42.

[5] R. Devaney, An Introduction to Chaotic Dynamical Systems, Addison-Wesley Publishing Company, Inc, 1989.

[6] O. Diekmann, S. A. van Gils, S. M. V. Lunel, and H. O. Walther, Delay Equations. Functional-, Complex-, and Nonlinear Analysis, Springer, New York, 1995.

[7] S. F. Ellermeyer, Competition in the chemostat, asymptotic behvior of a model with delayed response in growth, SIAM Journal of Applied Mathematics 54 (1994), 456-465.

[8] T. FARIA, Global attractivity in scalar delayed differential equations with applications to population dynamics, Journal of Mathematical Analysis and Applications 289 (2004), 35-54.

[9] S. A. H. GERITZ And É. KISDI, Mathematical ecology: why mechanistic models, Journal of Mathematical Biology (Perspectives) 65 (2012), 1411-1415.

[10] K. Gopals amy, Stability and Oscillations in Delay Differential Equations of Population Dynamics, Kluwer Academic Publishers, Dordrecht, 1992.

[11] J. GuCkenheimer And P. Holmes, Nonlinear Oscillations, Dynamical Systems, and Bifurcations of Vector Fields, Springer-Verlag, 1983. 
[12] I. GyőRI AND S. I. TROFImchuK, Global attractivity in $x^{\prime}(t)=-\delta x(t)+p f(x(t-\tau))$, Dynamic Systems and Applications 8 (1999), 197-210.

[13] J. K. Hale and S. M. Verduyn Lunel, Introduction to Functional Differential Equations, Springer, 1993.

[14] M. W. HiRsCh, H. L. SMith, AND X.-Q. Zhao, Chain transitivity, attractivity, and strong repellors for semidynamical systems, Journal of Dynamics and Differential Equations 13, 1 (2001), 107-131.

[15] C. S. Holling, Some characteristics of simple types of predation and parasitism, The Canadian Entomologist 91, 7 (1959), 385-398.

[16] G. E. Hutchinson, Circular causal systems in ecology, Annals of the New York Academy of Sciences 50, 4 (1948), 221-246.

[17] D. W. Jordan And P. Smith, Nonlinear Ordinary Differential Equations, Clarendon Press, Oxford, second edition, 1990.

[18] B. W. Kool, M. P. Boer, And S. A. L. M. Kooljman, On the use of the logistic equation in models of food chains, Bulletin of Mathematical Biology 60 (1998), 231-246.

[19] Y. Kuang, Delay Differential Equations in Population Dynamics, Academic Press, London, 1993.

[20] J. P. LASALLE, Some extensions of Lyapunovs second method, IRE Transactions of Circuit Theory, CT-7 (1960), 520-527.

[21] E. LIZ, Delayed logistic population models revisited, Publicacions Matemátiques, EXTRA (2014), 309-331.

[22] E. LIZ AND G. RöST, Dichotomy results for delay differential equations with negative Schwartzian derivative, Nonlinear Analysis: Real World Applications 11 (2010), 1422-1430.

[23] J. Mallet-Paret And G. R. Sell, The Poincaré-Bendixson theorem for monotone cyclic feedback systems with delay, Journal of Differential Equations 125 (1996), 441-489.

[24] A. J. Nicholson, An outline of the dynamics of animal populations, Australian Journal of Zoology 2 (1954), 9-65.

[25] A. J. Nicholson, The self-adjustment of populations to chance, Cold Spring Harbor Symposia on Quantitative Biology, 22 (1957), 153-173.

[26] R. M. Nisbet And W. S. C. Gurney, Modelling Fluctuating Populations, The Blackburn Press, P. O. Box 287, Caldwell, New Jersey, 07006 USA, 1982.

[27] W. Rudin, Principles of Mathematical Analysis, McGraw-Hill, Auckland, third edition, 1987.

[28] D. Singer, Stable orbits and bifurcation of maps of the interval, SIAM Journal of Applied Mathematics 35, 2 (1978), 260-267.

[29] H. L. Smith, Monotone Dynamical Systems: An Introduction to the Theory of Competitive and Cooperative Systems, Providence, R.I., American Mathematical Society, 1995.

[30] H. L. SMith, An Introduction to Delay Differential Equations with Applications to Life Sciences, Springer, 2011.

[31] H. L. Smith and P. Waltman, The Theory of the Chemostat: Dynamics of Microbial Competition, Cambridge University Press, 1995.

[32] J. W. So AND J. S. YU, Global attractivity for a population model with time delay, Proceedings of the American Mathematical Society 123, 9 (1995), 2687-2694.

[33] H. R. ThIEME, Convergence results and a Poincaré-Bendixson trichotomy for asymptotically autonomous differential equations, Journal of Mathematical Biology 30 (1992), 755-763.

[34] P. F. VERHUlst, Notice sur la loi que la population suit dans son accroisement, Corr. Math. et Phys. 10 (1838), 113-121.

[35] E. M. WRIGHT, A non-linear difference-differential equation, Journal für die Reine und Angewandte Mathematik, 194 (1955), 66-87.

[36] X. XIE, Uniqueness and stability of slowly oscillating periodic solutions of delay equations with unbounded nonlinearity, Journal of Differential Equations 103 (1993), 350-374. 